\title{
THE IMPACT OF COGNITIVE CONTROL ON CHILDREN'S GOAL MONITORING IN A TIME-BASED PROSPECTIVE MEMORY TASK
}

Caitlin E. V. Mahy ${ }^{1}$, Babett Voigt ${ }^{2}$, Nicola Ballhausen ${ }^{2}$, Katharina Schnitzspahn ${ }^{2}$, Judi Ellis ${ }^{3}, \&$

\author{
Matthias Kliegel ${ }^{2}$ \\ ${ }^{1}$ Brock University \\ ${ }^{2}$ University of Geneva \\ ${ }^{3}$ University of Reading
}

Corresponding Author:

Caitlin Mahy

Brock University

Department of Psychology

500 Glenridge Avenue

St Catharines, ON L2S 3A1

E-mail: caitlin.mahy@brocku.ca

\section{Acknowledgments}

Preparation of the manuscript was funded by a grant of the German Research Foundation (DFG) and a Swiss Government Scholarship to CEVM. 


\begin{abstract}
The present study investigated whether developmental changes in cognitive control may underlie improvements of time-based prospective memory. Five-, 7-, 9-, and 11-year-olds $(\mathrm{N}=$ 166) completed a driving simulation task (ongoing task) in which they had to refuel their vehicle at specific points in time (PM task). The availability of cognitive control resources was experimentally manipulated by imposing a secondary task that required divided attention. Children completed the driving simulation task both in a full attention condition and a divided attention condition where they had to carry out a secondary task. Results revealed that older children performed better than younger children on the ongoing task and PM task. Children performed worse on the ongoing and PM tasks in the divided attention condition compared to the full attention condition. With respect to time monitoring in the final interval prior to the PM target, divided attention interacted with age such that older children's time monitoring was more negatively affected by the secondary task compared to younger children. Results are discussed in terms of developmental shifts from reactive to proactive monitoring strategies. Keywords: prospective memory, divided attention, time monitoring, reactive control, proactive control, inhibition
\end{abstract}


A critical means to achieving successful future-oriented behavior is cognitive control, defined as the ability to flexibly regulate cognition in the service of goal-directed behavior. Cognitive control is the basis for self-initiated and flexible behavior and subsumes a set of executive functions including working memory, inhibition, cognitive flexibility, and monitoring (Miyake, Friedman, Emerson, Witzki, Howerter, \& Wager, 2000). This type of control is essential to be able to overcome rigid and inflexible patterns of behavior characteristic of very young children who often show perseveration across a variety of tasks (Kharitonova, Chien, Colunga, \& Munakata, 2009; Piaget, 1954; Zelazo, Frye, \& Rapus, 1996). In fact, overcoming perseveration is a developmental milestone that predicts later academic achievement, health outcomes, and even income (e.g., Blair \& Razza, 2007; Moffitt et al., 2011).

Cognitive control can be accomplished using two strategies: proactive and reactive control (e.g., Braver, Gray, \& Burgess, 2007). Proactive control involves resource-demanding direction of attention toward task-relevant information allowing for self-directed mental representation of goal-related information in anticipation of one's goal. In contrast, reactive control is less demanding and requires an external cue in order for the goal-related information to be activated. Cognitive control is particularly necessary under demanding task conditions such as when one must divide attention between two tasks.

The development of cognitive control occurs gradually over childhood and adolescence with the development of the prefrontal cortex (Booth et al., 2003; Bunge et al., 2002; Koechlin, Ody, \& Kouneiher, 2003; Lamm, White, McDermott, \& Fox, 2012; MacDonald et al., 2000; Miller, 2000). Munakata, Snyder, and Chatham (2012) describe the development of cognitive control in terms of a transition from reactive and externally driven control to proactive selfdirected control (between 3- and 8-year-olds). This achievement allows for children's behavior 
to become more flexible, anticipatory, and self-directed over development and represents a key change in the way children approach and perform cognitively demanding tasks. Chatham, Frank, and Munakata (2009) provided evidence that supports this developmental shift. They found that 8-year-olds resembled adults in their proactive use of cognitive control (indexed by behavioral measures and pupillometry), whereas 3.5-year-olds showed a more reactive strategy, responding to events as they occurred suggesting that proactive control becomes more efficient between the preschool and early childhood years.

Importantly, the developmental shift to the more frequent use of resource-demanding proactive control strategies has been suggested to support future-oriented thinking such as monitoring for cues during the delayed execution of intentions (Munakata, Snyder, \& Chatham, 2012). Based on this literature, we predicted that between preschool-age and school-age, children's ability to remember to carry out future intentions and time monitoring may become more sophisticated as they become increasingly able to adapt proactive control strategies. For this reason, school-aged compared to preschool children's future-oriented behavior may also be more negatively affected by interference that consumes attentional resources as these resources are needed for applying proactive control strategies. The current study aimed to test these predictions.

The ability to remember to carry out one's future intentions in the future is called prospective memory (PM; Einstein \& McDaniel, 1990). Examples of PM tasks in everyday life include remembering to take a medication at a certain time and remembering to pass a message on to a friend the next time you see them. One important feature of PM tasks is that they have to be performed while one is simultaneously engaged in a competing activity; a so-called ongoing task (McDaniel \& Einstein, 2000). PM tasks fall into two broad categories: event-based tasks 
that require an intention to be carried out in response to a certain event and time-based tasks that require an intention to be carried out at a specific point in time or after an allotted time has passed. In contrast to an event-based PM task where the occurrence of the target event is fairly unpredictable, the target time is predictable in a time-based task. Thus, engaging in preparatory time monitoring based on proactive control should benefit PM performance in a time-based task. Applying a proactive strategy in a time-based PM task may mean self-initiated intention execution based on internally generated, temporal representations, whereas a reactive strategy may involve intention execution in response to a specific, external temporal cue (e.g. a clock) without preparation in terms of anticipation of the approaching target time point (Snyder \& Munakata, 2010). PM that relies on proactive control should require more attentional resources compared to reactive control, but should also result in more reliable execution of the intended action. Therefore, older children's superior performance in time-based PM tasks may result from their ability to proactively regulate their monitoring behavior and young children's poorer PM might result from younger children's over reliance on reactive control strategies. Therefore, time-based PM tasks may be especially useful for examining the developmental shift from reactive to proactive control and its role in the development of future-oriented behavior (Snyder \& Munakata, 2010).

Developmental studies of PM indicate that it follows an inverted U-shape pattern across the lifespan (Zimmermann \& Meier, 2006; Zöllig et al., 2007). Research on the development of event-based PM across childhood has now established age-related increases from the early preschool years (Guajardo \& Best, 2000; Kliegel \& Jäger, 2009; Kvavilashvili, Ebdon, \& Messer, 2001; Mahy \& Moses, 2011) until later in adolescence (Shum et al., 2008). For example, increases in event-based PM have been documented in preschool children using a variety of tasks 
including computer simulation driving games (Kliegel et al., 2013) as well as simpler card sorting tasks (Ford et al., 2012; Kvavilashvili, Ebdon, \& Messer, 2001; Mahy \& Moses, 2011; Mahy, Moses, \& Kliegel, in press).

The development of time-based PM, in contrast to event-based PM, has been much less studied, particularly in young children. Recent evidence suggests that time-based PM may be observed as early as the kindergarten years: one such study showed that kindergarten children can successfully perform a time-based PM task that required using an hour glass as a timeequivalent (Aberle \& Kliegel, 2010). Much of the research on time-based PM has focused on children from 6- to 12-years-old and has shown age-related improvements in PM during this period (e.g., Kerns, 2000; Mackinlay, Kliegel, \& Mäntylä, 2009).

These studies also showed that for successful time-based PM, it is essential to monitor the passage of time in order to achieve the goal to carry out the PM task in a timely manner (e.g., Mackinlay, Kliegel, \& Mäntylä, 2009). As described above, time monitoring can be supported by reactive or proactive control processes depending on participants' attentional resources (that may vary by age or an experimental manipulation). In the present paper we argue that reactive time monitoring may be demonstrated by greater reliance on external time keeping devices while proactive time monitoring may involve internally generated temporal information (i.e., an internally constructed time model that has to initially be calibrated and reduces reliance on external time keeping devices). Due to developmental increases in attentional capacity, older children are likely to use a more sophisticated proactive monitoring strategy whereas younger children are likely to use a reactive monitoring strategy due to more limited attentional resources.

In support of this age-related shift from reactive to proactive control, patterns of time monitoring during the performance of a PM task tend to be more strategic with increasing age 
during childhood (e.g., Mackinlay, Kliegel, \& Mäntylä, 2009; Voigt et al., 2011, but see Mäntylä, Carelli, and Forman, 2007) becoming U-shaped or J-shaped, indicating that children initially calibrate themselves to the time by checking more, followed by a period of less checking, and finally a period with the highest amounts of checking just prior to the target time (Ceci \& Bronfenbrenner, 1985; Kerns, 2000). Recently, Voigt et al. (in press) showed that this increase in time monitoring shortly before appearance of the PM targets predicted children's PM performance better than overall amount of clock checking. Therefore, when strategic time monitoring occurs within the task (possibly due to developing proactive control) it may be more effective and therefore predictive of children's time-based PM performance compared to a high overall amount of time monitoring. To the best of our knowledge, Voigt et al. (in press) have been the only group to directly examine the prediction that time monitoring near the end of the interval may be more important than time monitoring throughout the entire time interval.

It has been suggested and initially tested that a number of abilities involving cognitive control are associated with PM development across the lifespan (Fish et al., 2007; Kliegel, Ramuschkat, \& Martin, 2003; Mahy \& Moses, 2011; Martin, Kliegel, \& McDaniel, 2003). Several studies have documented positive correlations between children's time- and event-based PM and working memory, inhibition, planning, and set-shifting abilities (e.g., Ford et al., 2012; Kerns, 2000; Kretschmer et al., 2013; Mackinlay, Kliegel, \& Mäntylä, 2009; Mahy \& Moses, 2011; Mahy, Moses, \& Kliegel, in press; Mäntylä, Carelli, \& Forman, 2007; Shum et al., 2008; Ward et al., 2005; Yang, Chan, \& Shum, 2011). For example, Kerns (2000) found that 7- to 12year-olds' time-based PM during a driving simulation task was related to their performance on inhibition, working memory, and set shifting. Further, Shum et al. (2008) found that 8- to 13year-olds' event-based PM was related to spontaneous verbal fluency, working memory, 
inhibition, and cognitive flexibility but only in the PM task that placed high demands on cognitive control. Direct evidence that shows that cognitive control, particularly the shift from reactive to proactive control, underlies developmental growth of time-based PM from preschoolage to adolescence is still lacking.

To date, only one study with children has used an experimental manipulation of available attentional resources (by including a secondary task in addition to the PM task) to reduce the likelihood of recruiting proactive control during time monitoring. Voigt et al. (in press) manipulated the need for working memory resources in the Dresden Cruiser task and found that age interacted with demand for working memory resources such that older children's PM and time monitoring were more negatively affected by a secondary task requiring working memory resources than younger children. However, some researchers have suggested that inhibitory control is a critical aspect of cognitive control (e.g., Munakata et al., 2011). Therefore, the aim of the current study is to follow-up on the findings of Voigt et al. to examine the impact of a manipulation of cognitive control focusing on inhibitory control resources rather than working memory resources to further examine the prediction that older children may be more negatively affected by a secondary task that demands cognitive control resources than younger children. Recent evidence suggests that working memory and inhibition are behaviorally dissociable processes in children (Wright \& Diamond, 2014) and thus these two abilities may have different roles in PM. In order to examine the impact of inhibition in a secondary task, we used the same the task parameters and participant age groups in the current study as in Voigt et al.'s study but changed the nature of the secondary task (from a working memory to an inhibition task). The current study is a follow-up designed to explicitly address whether the initial results from Voigt et al. generalize to other secondary tasks or were a specific result of the use of a working 
memory task. This strategy is a critical to pinning down the cognitive processes involved in maintaining and realizing a PM intention.

Based on the present literature, we predict that: (1) the developmental increase in timebased PM during childhood will be driven by a transition from monitoring of external temporal cues to monitoring of internally generated temporal representations (indicated by an increasing frequency of clock checks just prior to the target time) and (2) this transition will be fostered by a developmental shift from using less demanding reactive control strategies to proactive control strategies that put a high demand on attentional resources. To test these predictions, the current study will experimentally manipulate the available attentional resources of younger and older children by adding a secondary task that requires attentional resources that could otherwise be used for time monitoring in the context of the PM task. If young children rely on reactive control strategies in the PM task and as such consume fewer attentional resources, then one might expect that the addition of a secondary task might not disrupt their time monitoring and PM as much as that of older children. In contrast, older children may rely on proactive control strategies for completion of the PM task thereby consuming a high amount of attentional resources. Hence, for older children there might be more interference between secondary task performance and time monitoring during the PM task. Therefore, based on the proposed developmental shift from reactive to proactive control, we predict that a secondary task that requires additional cognitive control resources will have a larger relative impact on older children's PM and time monitoring behavior compared to younger children. Further, we sought to examine if time monitoring behavior, particularly time monitoring in the final interval (as an indicator of different monitoring strategies), predicted time-based PM performance. 


\section{Participants}

The sample included 189 typically developing children aged 5 to 12 years $(M=8.52, S D$ $=2.18$ ). Children were assigned to age groups accordingly: 5-year-olds (4.83 to 6.17), 7-yearolds (6.83 to 8.17), 9-year-olds (8.83 to 10.17 ) and 11-year-olds (10.83 to 12.17). Recruitment took place in local kindergartens, primary, and secondary schools. According to predefined inclusion criteria, we excluded data from 23 children due to: parent-report of developmental problems such as attention deficit hyperactivity disorder $(n=4)$, retrospective memory failure for the prospective task instruction $(n=1)$, technical problems with the computer equipment $(n=$ 12), and experimenter error $(n=6)$. The final sample consisted of 166 children (84 girls): 405 year-olds, 43 7-year-olds, 43 9-year-olds, and 40 11-year-olds.

\section{Materials}

Prospective Memory Paradigm

(a). Ongoing Task. The ongoing task was the Dresden Cruiser (Voigt et al., 2011), a driving simulation game originally developed by Kerns (2000) that requires children to accomplish two goals in parallel: (1) to drive a target vehicle on a road without crashing into other cars and (2) to refuel the car when the fuel is low. Participants had to drive a car on a twodimensional road displayed vertically on a computer monitor. The road had three parallel lanes, with other vehicles driving in the same direction on the road. The car was controlled by a gamepad (Thrustmaster FireStorm Digital 3 Gamepad) on the horizontal (left-right), but not the vertical (forward-backward) axis. The ongoing task required participants to pass other cars without hitting them to earn points. A game score was permanently displayed in the lower right corner of the screen during the game to increase children's motivation to do well. To prospectively account for possible differences in ongoing task performance, the difficulty of the 
driving game was adapted to each participant's individual performance level (number of car crashes) on a baseline block. There were five difficulty levels of the Dresden Cruiser that varied the number of other cars presented on the road per minute (ranging from 25 to 65 cars per minute). Children were assigned to one of five levels of the ongoing task (based on the percentage of car crashes during the baseline measure of ongoing task performance) that had been previously normed on a sample of 336 children aged 5 to 11 years (level one indicating the lowest $20^{\text {th }}$ percentile performance to level five indicating the highest $20^{\text {th }}$ percentile performance). The rate of car crashes (car crashes divided by the number of cars presented per minute) was used as the measure of ongoing task performance.

(b). Prospective Memory Task. The time-based PM task required children to remember to refuel their car (by pressing a button while driving) when the fuel was low. The fuel level was displayed on a gauge that children could check by pressing a button (to show the fuel gauge for three seconds in the corner of the screen). By pressing a second button on the gamepad, participants could refuel the car whenever the fuel gauge dropped into the red area (indicating that the tank was less than $1 / 4$ full). To increase task motivation, children received 100 points each time they refueled the car within the appropriate timeframe (in contrast, children received 33 points for passing a car). If the car ran out of gas, the tank was refilled automatically without any indication that there was a failure to refuel. A test block consisted of four one-minute trials and thus four opportunities to complete the PM task. In each trial, the car had to be refilled after 50 seconds of driving when the fuel gauge indicated the tank was only $1 / 4^{\text {th }}$ full, within 10 seconds before the tank was refilled automatically. Children were not given any information about the temporal characteristics of the task. The number of correct (i.e., timely) refuels served as the measure of PM performance for a maximum score of four. 
Time (goal) monitoring was measured by recording the number of times the children checked the fuel gauge prior to each PM target time. Following the standard procedure in analyzing time monitoring patterns (e.g., Kerns, 2000; Kliegel et al., 2005), the number of gauge checks across the length of one trial was analyzed by dividing it into four intervals. The number of checks was tallied within these four separate intervals, with the fourth interval being just prior to the PM target time. This was done for all four trials, resulting in 16 single intervals over the course of one test block. After children had completed the Dresden Cruiser, they were asked to recall the instructions and only children who could remember the PM task instructions were included in data analysis.

(c). Secondary Task. A manipulation was used to vary demands on cognitive control resources during the PM task. All participants performed the Dresden Cruiser in two consecutive test blocks (full and divided attention). In the full attention condition participants worked on the time-based PM task only (low demand on cognitive control). In the divided attention condition they completed the time-based PM task while concurrently executing a verbal labeling task that required inhibitory processes (high demand on cognitive control). Whether children received the full or divided attention condition first was counterbalanced and children were randomly assigned to the two orders.

This secondary task was used to manipulate the amount of cognitive control (inhibition) resources available for performance on the PM task and was adapted from Christensen et al. (2011). Children heard familiar German words (e.g. brother, queen, book) belonging to three categories (i.e., male, female, or object). All words were consecutively presented via earphones, lasted for one second, and were followed by a response window in which children could respond. Participants had to indicate verbally the category of the word itself. In order to increase demand 
on cognitive control, a male voice read all the female words and a female voice read all the male words so that children had to ignore the gender of the voice in order to verbally respond to the gender of the word as fast and accurately as they could. When the objects words were read (by a male or female voice) children had to response "thing" ensuring that they did not simply adopt a strategy of always saying the opposite gender to the voice that read the word. The error rate (including incorrect responses and failures to response divided by the number of trials) served as indicator for children's performance. In order to calibrate difficulty of the secondary task for the different age groups, the following parameters were applied based on prior pilot testing of 32 children (aged 5- to 11-years) that produced less than a $20 \%$ error rate on trials with divided attention in the baseline condition: (a) the length of the allowed response time window after stimuli presentation was two seconds for 11-year-olds, three seconds for 9-year-olds, four seconds for 7-year-olds and five seconds for 5-year-olds, (b) the number of trials in the test block was 80 trials for 11-year-olds, 60 trials for 9-year-olds, 48 trials for 7-year-olds and 40 trials for all 5-year-olds and (c) 5- and 7-year-olds children were instructed to respond to word gender with girl or boy, whereas 9- and 11-year-olds were instructed to respond with woman or man. In parallel to the duration of the PM task, the secondary task lasted four minutes in the test blocks. The experimenter raised a red flag in children's direct sight, if he or she failed to respond to two consecutive trials of the secondary task, to signal the need to respond to the secondary task.

\section{Procedure}

Children were tested individually in 60 to 80 minute testing sessions. Figure 1 shows a diagram of the order in which tasks were performed. The session began with the introduction of the secondary task. The experimenter familiarized participants with the sounds of all words from each category using a PowerPoint presentation with pictures for each word. Then, participants 
received the task instructions and the experimenter demonstrated two examples for each category. Children performed a practice trial (secondary task only, 12 trials for all children) followed by a baseline block ( 1 minute, increasing number of trials with increasing age). Next, children were introduced to the ongoing task of the Dresden Cruiser. When children could accurately repeat the instructions for this task, they played a one-minute practice trial (ongoing task only) to familiarize themselves with the driving component of the game. Then, children completed a second baseline block with the ongoing task of the Dresden Cruiser and the secondary task simultaneously (1 min) without the PM task. Based on the ongoing task performance in this baseline, the difficulty of the Dresden Cruiser was adapted to the appropriate level. The experimenter then provided the PM task instructions and children had to demonstrate understanding of the instructions by verbally recalling the rules of the game. However, in order to implement a delay between task instructions and subsequent execution of the PM task (see Ellis \& Kvavilashvili, 2000), the experimenter administered the Vocabulary scale of the HAWIVA-III or the HAWIK-IV. After completing the Vocabulary scale, children were asked to play the first test block, which was either a PM full attention test block (ongoing and PM task) or a PM divided attention test block (ongoing task, PM task, and the secondary task), without any further reminding of the need to refuel (PM task). Afterward the experimenter repeated the instructions for the PM task and a second delay phase involving the administration of the Matrix Reasoning subscale of the HAWIVA-III or the HAWIK-IV followed. Then children completed the second test block. Each test block took 4 minutes. After children had completed both test blocks, retrospective memory for task instruction was confirmed. Children were thanked and received a five Euro voucher for a local toy store. 
Results

Table 1 shows means and standard deviations for performance on the PM task and ongoing task for the full and divided attention condition, and secondary task performance in the divided attention condition as well as at baseline.

[Insert Table 1 here]

Secondary Task Performance by Age in Baseline versus Divided Attention Condition

A 2 (Condition: baseline vs. divided attention) X 4 (Age group: 5- vs. 7- vs. 9- vs. 11year-olds) mixed ANOVA on performance on the secondary task revealed that there was a main effect of condition on children's performance, $F(1,162)=191.94, p<.001, \eta_{p}{ }^{2}=.54$. Children had a significantly higher error rate on the secondary task when they also were carrying on the PM and OT task $(M=.17, S D=.15)$ compared to the baseline condition when they performed it alone $(M=.03, S D=.06)$. There was also a significant effect of age on secondary task

performance, $F(3,162)=17.98, p<.001, \eta_{p}{ }^{2}=.25$, which was driven by poorer performance of 5 -year-olds compared to the older age groups, $t(162)=.10, p<.001$. There was an interaction between condition and age group, $F(3,162)=9.46, p<.001, \eta_{p}^{2}=.25$. Follow-up comparisons showed that 5-year-olds error rate was much higher than the older age groups on the secondary task in the divided attention condition, $t(162)=8.04, p<.001$, but 5-year-olds did not differ in their error rates from older children on the secondary task in the baseline condition, $t(162)=$ $1.09, p=.28$.

The Impact of Attention and Age on Ongoing Task Performance

A 2 (Attention: full vs. divided) X 4 (Age group: 5- vs. 7- vs. 9- vs. 11-year-olds) mixed ANOVA on ongoing task performance was conducted. Results indicated a main effect of attention, $F(1,159)=5.65, p=.019, \eta_{p}^{2}=.034$, such that children hit more cars when they were 
engaged in the divided attention condition compared to the full attention condition. There was an effect of age on ongoing task performance, $F(3,159)=33.86, p<.001, \eta_{p}^{2}=.39$, with a linear increase in ongoing task performance from 5-years-old to 11-years-old, $t(159)=.11, p<.001$. There was no interaction between attention condition and age, $F(3,161)=.50, p=.68, \eta_{p}{ }^{2}=$ .01 .

\section{The Impact of Attention and Age on Prospective Memory Accuracy}

The impact of divided attention on PM by age was examined with a 2 (Attention: full vs. divided) by 4 (Age group: 5- vs. 7- vs. 9- vs. 11-year-olds) mixed ANOVA. Results revealed a main effect of the attention condition, $F(1,160)=24.17, p<.001, \eta_{p}{ }^{2}=.13$, such that there was better PM performance in the full attention condition compared to the divided attention condition, and of age group, $F(3,160)=16.36, p<.001, \eta_{p}{ }^{2}=.24$. Five-year-olds had significantly poorer PM performance compared to older children, $t(160)=.31, p<.001$, and 9year-olds performed worse than 11-year-olds, $t(160)=.15, p=.008$, but 7-year-olds' performance did not differ from 9- or 11-year-olds' PM performance $(p=.690)$. Age group and attention condition did not interact, $F(3,160)=.98, p=.404, \eta_{p}^{2}=.02$.

Given that there were unanticipated age differences in ongoing task performance, we carried out a 2 (Attention: full vs. divided) by 4 (Age group: 5- vs. 7- vs. 9- vs. 11-year-olds) ANCOVA with ongoing task performance during the divided attention condition as a covariate. Ongoing task performance was not a significant covariate of PM performance. Results revealed that the main effect of attention condition on PM performance disappeared after controlling for ongoing task performance, $F(1,157)=.369, p=.54, \eta_{p}{ }^{2}=.002$, although the main effect of age group on PM performance remained significant, $F(3,157)=9.48, p<.001, \eta_{p}^{2}=.153$. 
A 2 (Attention: full vs. divided) X 4 (Age group: 5- vs. 7- vs. 9- vs. 11-year-olds) mixed ANOVA on goal (time) monitoring in the final interval (just prior to the PM target time) revealed a main effect of attention, $F(1,160)=16.09, p<.001, \eta_{p}{ }^{2}=.09$, with children checking more during the full attention condition compared to the divided attention condition, and a main effect of age group, $F(1,160)=9.03, p<.001, \eta_{p}{ }^{2}=.15$. At the end of a trial, 5 -year-olds checked the fuel gauge less than the older children, $t(160)=1.89, p>.001$, and 9-year-olds checked the fuel gauge less than 11-year-olds, $t(160)=1.20, p=.018$, whereas 7-year-olds' fuel gauge checking did not differ from 9- and 11-year-olds' performance. These main effects, however, were qualified by an age by attention condition interaction, $F(3,160)=3.93, p=.010$, $\eta_{p}{ }^{2}=.07$. Simple effects revealed that older children's (9- and 11-year-olds) time monitoring suffered in the divided attention condition compared to the full attention condition, $F \mathrm{~s}(1,160)>$ 5.94, $p \mathrm{~s}<.02, \eta_{p}{ }^{2} \mathrm{~s}>.04$, whereas younger children (5- and 7-year-olds) fuel gauge monitoring was not negatively affected by the divided attention condition compared to the full attention condition, $F \mathrm{~s}(1,160)<1.03, p \mathrm{~s}>31, \eta_{p}{ }^{2} \mathrm{~s}<.006$ (see Figure 2). This interaction cannot be accounted for by age differences in secondary task performance, as when secondary task performance was added as a covariate the interaction between age and attention condition remained significant, $F(3,159)=4.09, p=.008, \eta_{p}{ }^{2}=.072$.

In order to control for age differences in ongoing task performance, a 2 (Attention: full vs. divided) X 4 (Age group: 5- vs. 7- vs. 9- vs. 11-year-olds) ANCOVA with ongoing task performance in the divided attention condition as a covariate was carried out on time monitoring performance. Ongoing task performance significantly co-varied with time monitoring during the final interval, $F(1,157)=5.143, p=.025, \eta_{p}{ }^{2}=.032$. After controlling for ongoing task, the main effect of the attention condition was no longer significant, $F(1,157)=1.39, p=.24, \eta_{p}{ }^{2}=.009$; 
however, the main effect of age group, $F(3,157)=5.46, p=.001, \eta_{p}{ }^{2}=.094$, and the interaction between age group and attention condition, $F(3,157)=3.70, p=.013, \eta_{p}{ }^{2}=.066$, remained significant.

[Insert Figure 2 here]

Age Differences in Increases in Time Monitoring across PM intervals

Given our prediction that younger children rely more on reactive control and older children rely more on proactive control, we examined differences in time checking across intervals to see if older children increased their time checking toward the PM target time compared to younger children. Greater increase in checking toward the target time would presumably support the existence of proactive monitoring whereas smaller increases would support the existence of less proactive and more reactive monitoring processes. To compare earlier and later checking, we compared the average amount of time monitoring in the first three time intervals compared to time monitoring in the fourth and final time interval.

For the full attention condition, a 2 (Time Interval: first three vs. last interval) by 4 (Age group: 5- vs. 7- vs. 9- vs. 11-year-olds) repeated measures ANOVA was carried out. Results revealed a main effect of time interval, $F(1,160)=153.21, p<.001, \eta_{p}{ }^{2}=.489$, with more checking in the final interval compared to the first three intervals collapsing across age groups. Age had an significant impact on performance, $F(3,160)=6.86, p<.001, \eta_{p}{ }^{2}=.114$, with 5year-olds checking less than older children $(p s<.046)$ but no differences between 7-, 9-, and 11 year-olds checking. A significant interaction between time interval and age emerged, $F(3,160)=$ 4.707, $p=.004, \eta_{p}{ }^{2}=.081$, such that older children (9- and 11-year-olds) showed a larger increase in time checking compared to 5-year-olds $(p<.043)$. 
For the divided attention condition, a 2 (Time Interval: first three vs. last interval) by 4 (Age group: 5- vs. 7- vs. 9- vs. 11-year-olds) repeated measures ANOVA was carried out. Results revealed a main effect of time interval indicating more checking in the final interval compared to the first three time intervals collapsed across age groups, $F(1,161)=88.29, p<$ $.001, \eta_{p}{ }^{2}=.35$. Age group had a significant impact on time monitoring, $F(3,160)=7.39, p$ $<.001, \eta_{p}{ }^{2}=.109$, with 5-year-olds checking less than 7- and 11-year-olds but no differently than 9-year-olds $(p s<.002)$. These main effects were qualified by a significant time interval by age interaction, $F(3,161)=5.24, p=.002, \eta_{p}{ }^{2}=.089$, such that 7 - and 11-year-old children showed a larger increase in time checking in the last interval versus the first three compared to 5-yearolds $(p s<.034)$.

\section{Predicting Prospective Memory Performance from Goal Monitoring Behavior}

Overall, children's time monitoring showed a linear increase as the target time approached in both the attention conditions, $F_{\mathrm{s}}(1,164)>82.45, p \mathrm{~s}<.001, \eta_{p}{ }^{2}>.34$ (see Figure 3). Given that past research has pointed the importance of increasing time checking just prior to the target time (Voigt et al., in press), we used the level of fuel gauge checking in the final interval to predict PM performance.

A regression was performed predicting PM performance from age and baseline levels of performance on the secondary task (step 1), and fuel gauge checking in the final interval (step 2) separately for the full attention and divided attention conditions.

In the full attention condition, results revealed that age and baseline secondary task performance significantly predicted PM performance in step $1, R^{2}=.156, F(2,162)=14.79, p<$ .001. In step 2, the time monitoring in the final interval predicted PM performance, $B=.756, t=$ 
$15.56, p<.001$. Increases in fuel gauge checking in the last interval accounted for $50.9 \%$ of the variance in PM performance, $R^{2}$ change $=.509, F$ change $(1,159)=242.03, p<.001$.

In the divided attention condition, results revealed that age and baseline secondary task performance predicted children's PM performance, $R^{2}=.135, F(2,161)=12.57, p<.001$. Fuel gauge checking in the final interval independently predicted PM performance, $B=.660, t=$ $12.05, p<.001$. Further, the amount of time monitoring in the final interval accounted for approximately $41 \%$ of the variance in PM performance, $R^{2}$ change $=.412, F$ change $(1,160)=$ 145.21, $p<.001$.

\section{Discussion}

The current study examined the impact of a task that required divided attention on 5- to 12-year-olds' ability to pursue goals and monitor goal attainment online indexed by time-based PM performance, ongoing task performance, and time monitoring behavior. The time-based PM task allowed for indexing of online goal monitoring via fuel gauge monitoring in a multiple goal situation (PM task, ongoing task, and secondary task). Therefore, both PM performance and time monitoring were equally important outcome variables. With regard to children's ongoing and PM task performance, results indicated a significant impact of age and of attention on children's PM task performance, with older children outperforming younger children and children performing better in the full attention condition compared to the divided attention condition. As predicted, older children showed a more marked increase in monitoring at the end of a trial and attentional demand had a more negative impact on time monitoring just prior to the appearance of PM cues in older children (9- and 11-year-olds) compared to younger children (5- and 7-yearolds). No age by cognitive control interaction was found for PM performance. Time monitoring 
in the final interval prior to the appearance of the PM cue was a significant predictor of PM performance in both attention conditions.

Findings of age-related improvement in time-based PM tasks in 5- to 12-year-olds are consistent with previous studies of children in this age range (e.g., Kerns, 2000) and the suggestion that even fairly young children can perform time-based PM tasks (see Aberle \& Kliegel, 2010) as even the youngest age group (i.e., 5-year-olds) did not perform at floor levels on the PM task. We suggest that a shift between reactive and proactive control during this age might explain the current findings in the realm of time monitoring (Chatham, Frank, \& Munakata, 2009). The superior performance of older children who likely are relying on more effective proactive control strategies rather than reactive control strategies is in accordance with this view.

The addition of a secondary task requiring divided attention had a negative effect on all children's PM and ongoing task performance independent of age. The effect of the secondary task on PM, however, can be accounted for by differences in ongoing task performance suggesting that the secondary task leads to worse performance on the ongoing task but not on the PM task itself.

In contrast to our prediction and to the findings of Voigt et al. (in press), impact of the secondary task on PM performance did not vary with age. At first glance, it seems that developmental increases in the PM task cannot be explained by age-related differences in cognitive control or that the present manipulation might have not been sufficient to differentially disrupt reactive and proactive processes supporting younger and older children's PM. This finding seems to pose a challenge for the idea that cognitive control shifts from reactive to proactive control, however, it is possible that due to the limited number of PM trials, time 
monitoring was a more sensitive measure to detect shifts from reactive to proactive strategies than PM accuracy. While there were only four PM trials, time monitoring was measured continuously and task demands did not limit the amount of time monitoring that a child could engage in. Differences between the current findings and those of Voigt et al. (in press) must be attributable to differences in the secondary task (working memory versus inhibition), as all other tasks parameters were the same. Perhaps the working memory task was more difficult than the current inhibition task and therefore more negatively affected older children's PM compared to younger children's PM. The inhibition task used in the current study might not have been difficult enough to disrupt PM performance but was challenging enough to negatively affect time monitoring whereas the working memory task in Voigt et al. may have been more difficult. Alternately, it is possible that working memory demand might have disrupted older children's PM more than younger children because working memory resources are needed throughout all phases of the PM task (particularly surrounding the time when the PM action must be carried out), whereas inhibitory resources may be more important to time monitoring but less necessary for carrying out the PM action. Future work should examine the impact of various forms of executive demands on different phases of the PM task and different stages of development.

Importantly, examining monitoring processes that predicted a large amount of variance in the PM task showed that the explanation that differences in cognitive control cannot explain agerelated differences is unlikely. Our prediction was that older children's time monitoring in the final interval would be more disrupted by adding the secondary task than younger children as the use of proactive control strategies becomes more likely with increasing age. This hypothesis was confirmed. Older children's (9- and 11-year-olds) time monitoring was more negatively affected by the secondary task than younger children's (5- and 7-year-olds), suggesting that young 
children's goal monitoring was not impacted because they may have adapted reactive control strategies that require less resources compared to proactive control strategies, whereas older children's fuel gauge checking was disrupted by the secondary task because they both consumed a high amount of limited attentional resources (see Munakata, Snyder, \& Chatham, 2012). Importantly, after controlling for performance on ongoing and secondary task, this age by attention condition interaction remained significant. These findings support the idea that younger compared to older children may adopt different cognitive control strategies for time monitoring during time-based PM tasks. These different cognitive approaches may underlie improvements in PM through childhood. However, despite the disruption to time monitoring behavior, older children still managed to perform quite well on the PM task in the divided attention condition. Therefore, it seems that processes other than time monitoring may have also been important in supporting older children's PM performance such as metacognitive knowledge or superior time estimation ability.

The overall pattern of fuel checking was more linear (Mäntylä, Carelli, \& Forman, 2007) than U- or J-shaped, as others have found (e.g., Ceci \& Bronfenbrenner, 1985; Mackinlay, Kliegel, \& Mäntylä, 2009). It seems that although children were anticipating the target time correctly as they increased their fuel gauge checking just prior to the time that they needed to refuel their vehicle, they did not show the typical calibration pattern at the start of the interval by checking more in order to adjust one's psychological clock. It is likely that due to the multiple trial structure of the PM task, children adjusted their psychological clock after the first trial and then showed a more J-shaped rather than U-shaped pattern of checking on later trials (see Voigt et al., 2011). Alternatively, perhaps it is more strategic and consumes fewer resources to forgo this initial calibration in favor of more focused time monitoring as the target time approaches. 
Because children were performing a fairly demanding ongoing task throughout the period of time monitoring, completing the PM task and the secondary task may have depleted the resources required to check the fuel gauge immediately after the target time.

An important finding of the current study was age differences in the relative increase in time monitoring from the first three time intervals compared to the last interval. In both full and divided attention conditions, older children increased their time monitoring more than 5-yearolds. This provides supporting evidence for the idea that younger children are relying more on reactive monitoring and therefore have less of an increase in their proactive monitoring strategies compared to older children whose proactive control strategies are likely more developed. However, the main effect of time interval collapsed across age shows that even 5-year-olds did increase their time monitoring in the final interval, just to a lesser extent than older children. This supports the findings of Voigt et al. (in press) who found that older children increased time monitoring across the time interval more than younger children in a similar PM task with a secondary task that disrupted working memory resources.

The amount of time monitoring in the final interval, just prior to the PM target time, was a strong predictor of PM performance in both the full and divided attention condition. Time monitoring in the final interval predicted over $40 \%$ of the variance in PM above and beyond age and baseline levels of secondary task performance. Despite the attentional demands of the secondary task, the amount of monitoring that occurred in the final interval was still critical to PM performance, which is not surprising given that attention paid to the fuel gauge level close to the target time should result in higher probabilities of carrying out the PM task in a timely manner. There are practical implications that arise from this finding for how to improve timebased PM in children, especially those who struggle with this ability: Children could be trained 
to increase time monitoring just prior to the target time rather than an increasing time monitoring in general during a time-based PM task.

Future studies should continue to examine the role of cognitive control in PM tasks. It is possible that age-differences in time monitoring can be interpreted in terms of children's shifts from relying on reactive to proactive control processes. Studies could use secondary tasks that vary in their level of cognitive or attentional demand in order to better examine the exact conditions that affect PM performance and time monitoring. The current Dresden Cruiser paradigm shows promise as a time-based PM task in that children between 5- and 12-years-olds did not show floor or ceiling effects on this task, and it allows for the measurement of PM, ongoing task, and time monitoring performance.

In sum, the current study established that a secondary task that competed for attentional resources had a negative impact on children's PM, ongoing task, and time monitoring performance. In particular, the presence of a secondary task had a negative impact on goal monitoring in the final interval just prior to the target time. This pattern was more pronounced for older children, indicating that this might have impacted their proactive control strategies whereas it may have not affected younger children as much because they may have relied on less demanding reactive monitoring processes. Finally, it showed that strategic time monitoring performance in the final interval predicted PM in both the full and divided attention conditions suggesting that the greater time monitoring prior to the PM target time is critical to successful PM. Future work should continue to use PM paradigms to examine the development of cognitive control as well as transitions from relying on reactive control in early childhood to proactive control in middle childhood. 


\section{References}

Aberle, I., \& Kliegel, M. (2010). Time-based prospective memory performance in young children. European Journal of Developmental Psychology, 7, 419-431.

Blair, C., \& Razza, R. P. (2007). Relating effortful control, executive function, and false belief understanding to emerging math and literacy ability in kindergarten. Child Development, 78, 647-663.

Booth, J. R., Burman, D. D., Meyer, J. R., Lei, Z., Trommer, B. L., Davenport, N. D., ... \& Mesulam, M. (2003). Neural development of selective attention and response inhibition. Neuroimage, 20, 737-751.

Braver, T. S., Gray, J. R., \& Burgess, G. C. (2007). Explaining the many varieties of working memory variation: Dual mechanisms of cognitive control. In A.R.A. Conway, C. Jarrold, M. J. Kane, A. Miyake, \& J. N. Towse (Eds.), Variation in working memory (p. 76-106). New York: Oxford.

Bunge, S. A., Dudukovic, N. M., Thomason, M. E., Vaidya, C. J., \& Gabrieli, J. D. (2002). Immature frontal lobe contributions to cognitive control in children: evidence from fMRI. Neuron, 33(2), 301-311.

Chatham, C. H., Frank, M. J., \& Munakata, Y. (2009). Pupillometric and behavioral markers of a developmental shift in the temporal dynamics of cognitive control. Proceedings of the National Academy of Sciences, 106, 5529-5533.

Christensen, T. A., Lockwood, J. L., Almryde, K. R., \& Plante, E. (2011). Neural substrates of attentive listening assessed with a novel auditory stroop task. Frontiers in Human Neuroscience, 4: 236. 
Davidson, M. C., Amso, D., Anderson, L. C., \& Diamond, A. (2006). Development of cognitive control and executive functions from 4 to 13 years: Evidence from manipulations of memory, inhibition, and task switching. Neuropsychologia, 44, 2037-2078.

d'Ydewalle, G., Bouckaert, D., \& Brunfaut, E. (2001). Age-related differences and complexity of ongoing activities in time-and event-based prospective memory. The American Journal of Psychology, 114, 411-423.

Einstein, G. O., \& McDaniel, M. A. (1990). Normal aging and prospective memory. Journal of Experimental Psychology: Learning, Memory, and Cognition, 16, 717-726.

Ellis, J., \& Kvavilashvili, L. (2000). Prospective memory in 2000: Past, present and future directions. Applied Cognitive Psychology, 14, S1-S9.

Fish, J., Evans, J. J., Nimmo, M., Martin, E., Kersel, D., Bateman, A., Wilson, B. A., \& Manly, T. (2007). Rehabilitation of executive dysfunction following brain injury: "Content-free" cueing improves everyday prospective memory performance. Neuropsychologia, 45, 1318-1330.

Guajardo, N. R., \& Best, D. L. (2000). Do preschoolers remember what to do? Incentive and external cues in prospective memory. Cognitive Development, 15, 75-97.

Kerns, K. (2000). The CyberCruiser: An investigation of development of prospective memory in children. Journal of the International Neuropsychological Society, 6, 62-70.

Kharitonova, M., Chien, S., Colunga, E., \& Munakata, Y. (2009). More than a matter of getting 'unstuck': flexible thinkers use more abstract representations than perseverators. Developmental Science, 12, 662-669. 
Kliegel, M., \& Jäger, T. (2007). The effects of age and cue-action reminders on event-based prospective memory performance in preschoolers. Cognitive Development, 22, 33-46.

Kliegel, M., Mahy, C. E. V., Voigt, B., Henry, J. D., Rendell, P. G., \& Aberle, I. (2013). The development of prospective memory in young school children: The impact of ongoing task absorption, cue salience, and cue location. Journal of Experimental Child Psychology, 116, 792-810.

Kliegel, M., Martin, M., McDaniel, M. A., \& Einstein, G. O. (2001). Varying the importance of a prospective memory task: Differential effects across time-and event-based prospective memory. Memory, 9, 1-11.

Kliegel, M., Ramuschkat, G., \& Martin, M. (2003). Executive functions and prospective memory performance in old age: an analysis of event-based and time-based prospective memory]. Zeitschrift für Gerontologie und Geriatrie, 36, 35-41.

Koechlin, E., Ody, C., \& Kouneiher, F. (2003). The architecture of cognitive control in the human prefrontal cortex. Science, 30, 1181-1185.

Kretschmer, A., Voigt, B., Friedrich, S., Pfeiffer, K., \& Kliegel, M. (in press). Time-based prospective memory in young children-Exploring executive functions as a developmental mechanism. Child Neuropsychology.

Kvavilashvili, L., Messer, D. J., \& Ebdon, P. (2001). Prospective memory in children: The effects of age and task interruption. Developmental Psychology, 37, 418-430.

Lamm, C., White, L. K., McDermott, J. M., \& Fox, N. A. (2012). Neural activation underlying cognitive control in the context of neutral and affectively charged pictures in children. Brain and Cognition, 79, 181-187. 
MacDonald, A. W., Cohen, J. D., Stenger, V. A., \& Carter, C. S. (2000). Dissociating the role of the dorsolateral prefrontal and anterior cingulate cortex in cognitive control. Science, 288, $1835-1838$.

Mackinlay, R. J., Kliegel, M., \& Mäntylä, T. (2009). Predictors of time-based prospective memory in children. Journal of Experimental Child Psychology, 102, 251-264.

Mahy, C. E. V., \& Moses, L. J. (2011). Executive functioning and prospective memory in young children. Cognitive Development, 26, 269-281.

Mahy, C. E. V., Moses, L. J., \& Kliegel, M. (in press). The impact of age, ongoing task difficulty, and cue salience on preschoolers' prospective memory performance: The role of executive function. Journal of Experimental Child Psychology.

Mäntylä, T., Carelli, M. G., \& Forman, H. (2007). Time monitoring and executive functioning in children and adults. Journal of Experimental Child Psychology, 96, 1-19.

Martin, M., Kliegel, M., \& McDaniel, M. A. (2003). The involvement of executive functions in prospective memory performance of adults. International Journal of Psychology, 38, 195-206.

Miller, E. K. (2000). The prefontral cortex and cognitive control. Nature Reviews Neuroscience, $1,59-65$.

Miyake, A., Friedman, N. P., Emerson, M. J., Witzki, A. H., Howerter, A., \& Wager, T. D. (2000). The unity and diversity of executive functions and their contributions to complex frontal lobe tasks: A latent variable analysis. Cognitive Psychology, 41, 49-100.

Moffitt, T. E., Arseneault, L., Belsky, D., Dickson, N., Hancox, R. J., Harrington, H., . . Caspi, A. (2011). A gradient of childhood self- control predicts health, wealth, and public safety. Proceedings of the National Academy of Sciences, USA, 108, 2693-2698. 
Munakata, Y., Herd, S. A., Chatham, C. H., Depue, B. E., Banich, M. T., \& O’Reilly, R. C. (2011). A unified framework for inhibitory control. Trends in Cognitive Sciences, 15, 453-459.

Munakata, Y., Snyder, H. R., \& Chatham, C. H. (2012). Developing cognitive control: Three key transitions. Current Directions in Psychological Science, 21, 71-77.

Petermann, F. \& Petermann, U. (Hrsg.). (2008). Hamburg-Wechsler-Intelligenztest für Kinder IV (HAWIK-IV) (2., ergänzte Aufl.). Bern: Huber.

Piaget, J. (1954). The construction of reality in the child. New York, NY: Basic Books.

Ricken, G., Fritz, A., Schuck, K. D., \& Preuß, U. (2007). Hannover-Wechsler-Intelligenztest für das Vorschulalter-III (HAWIVA-III). Bern: Hans Huber.

Schnitzspahn, K. M., Stahl, C., Zeintl, M., Kaller, C. P., \& Kliegel, M. (2013). The role of shifting, updating, and inhibition in prospective memory performance in young and older adults. Developmental Psychology, 49, 1544-1553.

Shum, D., Cross, B., Ford, R., \& Ownsworth, T. (2008). A developmental investigation of prospective memory: Effects of interruption. Child Neuropsychology, 14, 547-561.

Snyder, H. R., \& Munakata, Y. (2010). Becoming self-directed: Abstract representations support endogenous flexibility in children. Cognition, 116, 155-167.

Voigt, B., Aberle, I., Schonfeld, J., \& Kliegel, M. (2011). Time-based prospective memory in schoolchildren. Zeitschrift für Psychologie, 219, 92-99.

Voigt, B., Mahy, C. E. V., Ellis, J., Schnitzspahn, K., Altgassen, M., \& Kliegel, M. (in press). The development of time-based prospective memory in childhood: The role of working memory updating. Developmental Psychology. 
Yang, T. X., Chan, R. C., \& Shum, D. (2011). The development of prospective memory in typically developing children. Neuropsychology, 25, 342-352.

Zelazo, P. D. (2004). The development of conscious control in childhood. Trends in Cognitive Sciences, 8, 12-17.

Zelazo, P. D., \& Frye, D. (1998). Cognitive complexity and control: II. The development of executive function in childhood. Current Directions in Psychological Science, 7, 121126.

Zelazo, P. D., Frye, D., \& Rapus, T. (1996). An age-related dissociation between knowing rules and using them. Cognitive Development, 11, 37-63.

Zimmermann, T. D., \& Meier, B. (2006). The rise and decline of prospective memory performance across the lifespan. The Quarterly Journal of Experimental Psychology, 59, 2040-2046.

Zöllig, J., West, R., Martin, M., Altgassen, M., Lemke, U., \& Kliegel, M. (2007). Neural correlates of prospective memory across the lifespan. Neuropsychologia, 45, 3299-3314. 
Table 1

Means and standard deviations for prospective memory accuracy and ongoing task performance (car crash rate) in the full and divided attention conditions.

\begin{tabular}{|c|c|c|c|c|c|}
\hline & Age Group & 5-year-olds & 7-year-olds & 9-year-olds & 11-year-olds \\
\hline Baseline & $\begin{array}{l}\text { Secondary Task } \\
\text { Error Rate }\end{array}$ & $.039(.102)$ & $.027(.042)$ & $.020(.039)$ & $.033(.045)$ \\
\hline \multirow[t]{2}{*}{ Full attention } & $\begin{array}{l}\text { Prospective Memory } \\
\text { Hit Rate }\end{array}$ & $.327(.31)$ & $.628(.33)$ & $.625(.31)$ & $.750(.27)$ \\
\hline & $\begin{array}{l}\text { Ongoing Task } \\
\text { Performance } \\
\text { (Car Crash Rate) }\end{array}$ & $.312(.080)$ & $.235(.074)$ & $.186(.072)$ & $.160(.093)$ \\
\hline \multirow[t]{3}{*}{$\begin{array}{l}\text { Divided } \\
\text { Attention }\end{array}$} & $\begin{array}{l}\text { Prospective Memory } \\
\text { Hit Rate }\end{array}$ & $.237(.28)$ & $.535(.33)$ & $.419(.32)$ & $.606(.34)$ \\
\hline & $\begin{array}{l}\text { Ongoing Task } \\
\text { Performance } \\
\text { (Car Crash Rate) }\end{array}$ & $.316(.095)$ & $.252(.086)$ & $.208(.075)$ & $.170(.065)$ \\
\hline & $\begin{array}{l}\text { Secondary Task } \\
\text { Error Rate }\end{array}$ & .309 (.187) & $.148(.123)$ & $.097(.081)$ & $.132(.092)$ \\
\hline
\end{tabular}




\begin{tabular}{|c|c|c|c|c|c|c|c|c|}
\hline $\begin{array}{l}\text { Baseline } \\
\text { ST }\end{array}$ & $\begin{array}{l}\text { Baseline } \\
\text { OT and } \\
\text { ST }\end{array}$ & $\begin{array}{l}\text { Introduction } \\
\text { of PM task }\end{array}$ & $\begin{array}{l}\text { Delay } \\
\text { test of } \\
\text { general } \\
\text { abilities }\end{array}$ & $\begin{array}{l}\text { Test } \\
\text { Block 1: } \\
\text { OT + PM } \\
\text { or OT + } \\
\text { PM + ST }\end{array}$ & $\begin{array}{l}\text { Reminder } \\
\text { OT + PM }\end{array}$ & $\begin{array}{l}\text { Delay } \\
\text { test of } \\
\text { general } \\
\text { abilities }\end{array}$ & $\begin{array}{l}\text { Test Block } \\
\text { 2: OT + } \\
\text { PM or OT + } \\
\text { PM + ST }\end{array}$ & $\begin{array}{l}\text { Test of } \\
\text { retrospective } \\
\text { memory }\end{array}$ \\
\hline
\end{tabular}

Time

Figure 1

Schematic of the order of tasks in the procedure.

Note $-\mathrm{ST}=$ secondary task, $\mathrm{OT}=$ ongoing task, $\mathrm{PM}=$ prospective memory 


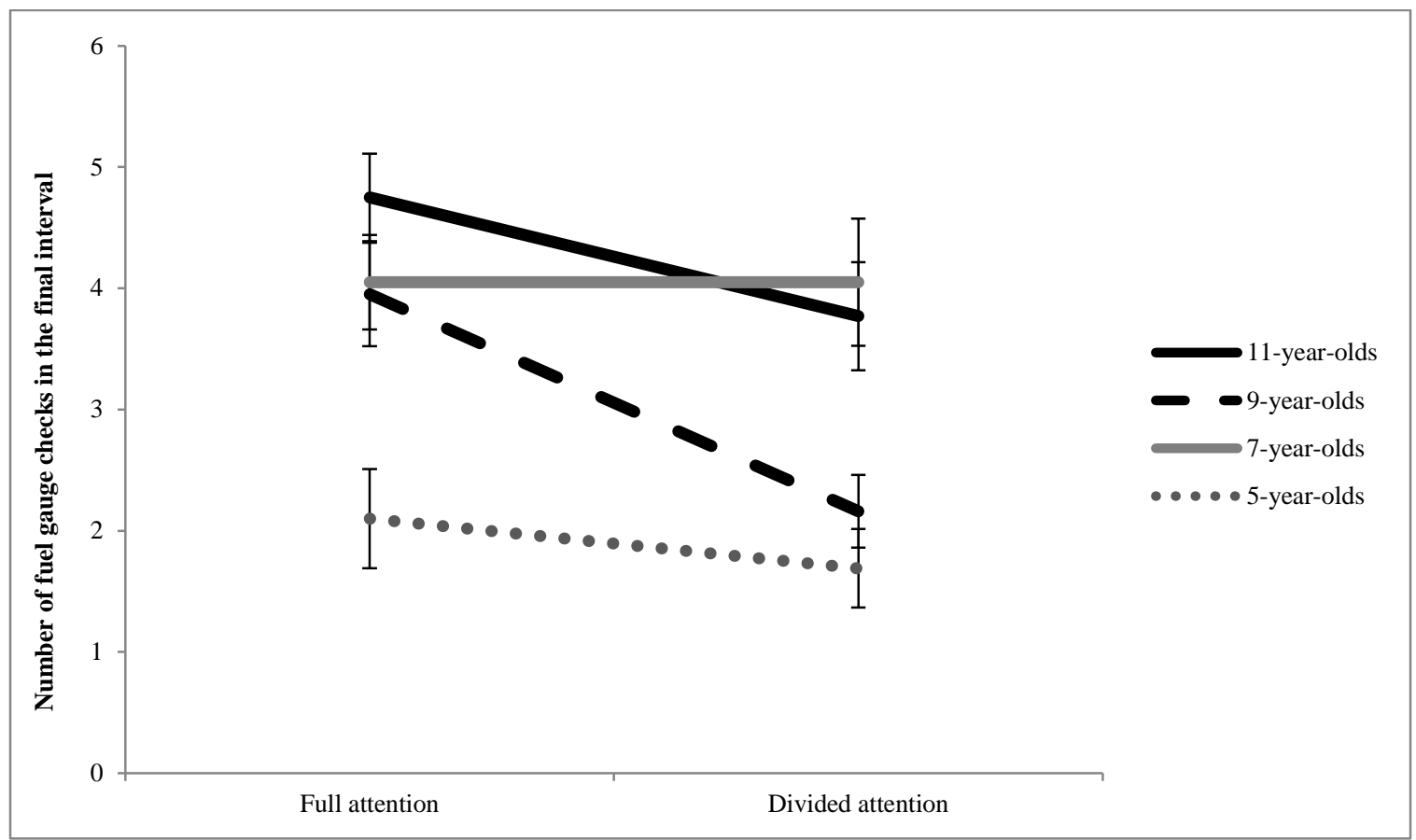

Figure 2

Fuel gauge checking in the final interval in the full attention and divided attention conditions by age group (error bars represent +/- 1 SEM). 


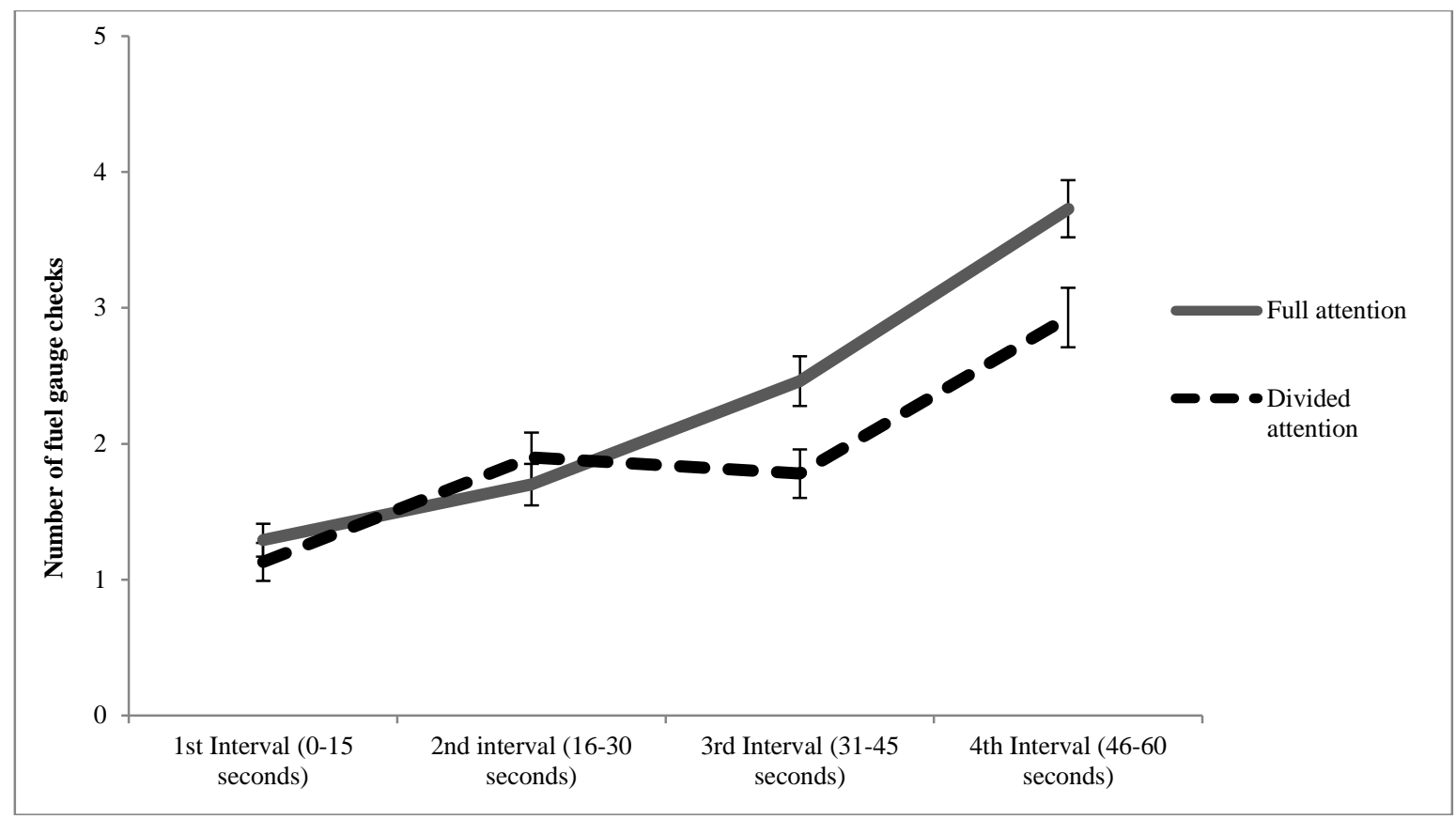

Figure 3

Fuel gauge checking during the four time intervals in the PM task in the full and divided attention conditions (error bars represent +/- 1 SEM). 